\title{
VITALIDAD DE LA FONOLOGÍA SEGMENTAL DEL MAPUDUNGUN DE ESCOLARES MAPUCHES DE TIRÚA ${ }^{1}$ \\ VITALITY OF MAPUDUNGUN SEGMENTAL PHONOLOGY IN MAPUCHE SCHOOL STUDENTS FROM TIRÚA.
}

\author{
Marisol Henríquez Barahona \\ mhenriquez@ucsc.cl \\ Dpto. de Lenguas \\ UCSC
}

\section{Resumen:}

En este artículo $^{2}$ describiremos la vitalidad del sistema fonológico del mapudungun de escolares lafkenches de Tirúa, VIII Región. En general, nos propusimos: identificar las principales transferencias fonético-fonológicas presentes en la fonología del mapuche que manejan estos escolares e interpretar las transferencias encontradas en términos del grado de vitalidad de la fonología de la lengua.

La muestra está conformada por un grupo de 20 escolares mapuches, bilingües en diversos grados, de entre 12 y 15 años de edad, que se encuentran cursando $7^{\circ}$ y $8^{\circ}$ año básico en escuelas rurales pertenecientes a dos comunidades de

\footnotetext{
${ }^{1}$ En este artículo, las transcripciones fonéticas y fonémicas se realizan de acuerdo con el Alfabeto Fonético Internacional, mientras que la escritura grafémica de las palabras en mapudungun se realiza de acuerdo con el Alfabeto Mapuche Unificado.

${ }^{2}$ Los resultados presentados en este artículo forman parte de la tesis doctoral de la autora: "Vitalidad fonológica del mapudungun en escolares mapuches pewenches y lafkenches de la VIII región del Bío-Bío”. Tesis para optar al grado de Doctor en Lingüística, Universidad de Concepción, 2013.
}

Recibido: 01/03/2016

Aceptado: 25/06/2016 
Tirúa. Para la elicitación del material fonológico, se aplicó a los participantes una lista léxica de 65 ítems, lo que se complementó con la narración oral de un cuento en mapudungun.

En este estudio hemos podido observar una serie de rasgos fónicos en el mapudungun de los niños de Tirúa, tales como transferencias, alternancias y reemplazos, que tienen directa relación con la influencia de las estructuras fonológicas del castellano y con los procesos incompletos de adquisición de la lengua vernácula. La situación fonológica de los niños es bastante homogénea en ambos sectores, pues el grado y la difusión de los fenómenos de transferencia se desarrollan de manera similar en ambas comunidades en estudio.

Palabras claves: Fonología del mapudungun, contacto mapudungun-castellano, transferencias fonológicas, vitalidad fonológica.

\section{Abstract:}

This paper describes the vitality of the phonological system of Mapudungun in Lafkenches school students from Tirúa, VIII Region. The identification of the main phoneticphonological transfer in the phonology of mapuche school students and the interpretation of transfers found in terms of the degree of vitality of language phonology are explored.

The sample was made up of a total of 20 seventh and eighth mapuche graders with different degrees of bilingualism, from two Tirúa local communities, whose age ranged between 12 and 15. For the elicitation of phonological features a lexical list of 65 items plus the oral narration of a mapudungun story were applied.

A series of phonic features, such as transfers, alternations and substitutions in mapudungun use were observed. These features are directly related to the influence of both, the phonological structures of Castellano language and the incomplete acquisition process of the vernacular language. 
The phonology in children is fairly homogeneous in both local communities, due to the fact that the degree and distribution of transfer phenomenon are equally developed in both communities.

Keywords: mapudungun phonology, contact mapudunguncastellano contact, phonological transfers, phonological vitality.

\section{Introducción: Contacto lingüístico y transferencia fonológica}

Varias investigaciones sociolingüísticas realizadas en Chile, han puesto de manifiesto la compleja situación que vive el mapudungun hoy en día. Sostienen que su vitalidad estaría seriamente comprometida, pues se encuentra en una fase de retroceso producto del contacto sistemático con el castellano, lo que se evidencia principalmente en la disminución del número de hablantes, en la pérdida de ámbitos de uso tradicionales y en el quiebre de la transmisión intergeneracional (Zúñiga, 2007; Gundermann et al., 2009; Lagos, 2012). Esta situación de vulnerabilidad se observa de manera más extrema en el segmento generacional de los jóvenes y niños mapuches (Salas, 1992; Duran et al, 2007; Zuñiga, 2007; Gunderman, 2009) quienes muestran los menores niveles de competencia en la lengua. Sin embargo esta situación no es extensiva a todo el segmento generacional, pues aún hay jóvenes y niños que mantienen su lengua como vehículo principal de comunicación al interior de sus familias, como es el caso de niños pewenches de comunidades del Alto Bío-Bío (Henríquez, 2014; 2015).

Se sabe que una de las posibles consecuencias del contacto lingüístico en un grupo o sociedad bilingüe es la influencia de una lengua sobre otra, tanto unidireccionalmente como bidireccionalmente, dependiendo 
de la relación de dominancia entre las lenguas en cuestión y de la historia sociolingüística de sus hablantes (Thomason y Kaufman, 1988; Thomason, 2001). De este modo, el contacto de lenguas da lugar a múltiples fenómenos que afectan a todos los niveles del sistema -fonología, morfología, sintaxis y vocabulario- (Thomason y Kaufman, 1988; Silva-Corvalán, 2001; Moreno Fernández, 2009), situación que se intensifica cuando se trata del contacto intenso y prolongado entre una lengua mayoritaria y una minoritaria. En estos casos, la primera puede influir a través de fenómenos de contacto como la transferencia lingüística en la lengua receptora.

Ahora bien, cuando esta situación de contacto se caracteriza por el desplazamiento linguístico, es posible constatar transferencia estructural, principalmente en los planos fonológicos y sintácticos de la lengua minoritaria (Thomason y Kaufman, 1988). Así, en el plano fonológico es posible observar variación y cambio por contacto. Estos procesos pueden enriquecer el inventario de unidades o pueden conducir a la pérdida de otras, llegando incluso a la convergencia de los sistemas en contacto. (Andersen, 1982; Kirschner, 1996; Grinevald, 1997).

Desde una perspectiva estructural, cualquier diferencia entre los sistemas puede constituirse en un estímulo para las transferencias (Sala, 1988; Gimeno y Gimeno, 2003). En este caso, los fonemas o sonidos que no existen más que en uno de los sistemas se adaptan al de la lengua receptora (Sala, 1988).

En nuestro estudio, al abordar las transferencias fonológicas desde el castellano hacia el chedungun nos centraremos principalmente en aquellos segmentos de la lengua vernácula que no tienen una contraparte en la matriz fonológica del castellano, puesto que probablemente serán estos fonemas los que tiendan a la inestabilidad, variación o 
cambio por procesos de transferencia (Andersen, 1982; Sala, 1988; Henríquez, 2004, 2013; Gimeno y Gimeno, 2003; Blas Arroyo, 2008; Henríquez y Salamanca, 2015).

\section{Estudios fonológicos del mapuche de Tirúa}

Existen varias descripciones fonológicas especializadas del mapuche hablado por adultos. De estas publicaciones, destacamos los trabajos de: Suárez (1959); Echeverría (1964); Salas (1976); Lagos (1981); ÁlvarezSantullano (1986a, 1986b); Sánchez (1989); Salamanca (1997); Salamanca y Quintrileo (2009) y Sadowsky, Painequeo, Salamanca y Avelino (2013), entre otros. Para el caso de los niños encontramos las descripciones de Henríquez (2013) y Henríquez y Salamanca (2012 y 2015).

Con respecto al mapuche de Tirúa, zona relevante para los propósitos de este estudio, destacamos el trabajo de Salamanca y Quintrileo (2009), quienes publican una descripción fonológica del mapuche hablado por adultos del sector. Según el análisis de estos autores, el mapuche hablado en Tirúa tiene 24 fonemas segmentales. De ellos, 6 son vocales: /i, e, a, ü, u, o/ y 18 son consonantes: /p, t, tr, č, k, v, ð, w, g, s, y, r, m, n, ), $\eta, 1, \times /$. Señalan, además, que, a diferencia de lo que sucede en otros dialectos, en el mapuche de esta zona, los sonidos interdentales [t], [n], [1] no se presentan como fonemas distintos, sino como variantes de las realizaciones alveolares. Asimismo, coinciden con Echeverría en que $[\Sigma]$ es un alófono de $/ \tau \Sigma /$ pero difieren de él, cuando asignan estatus fonémico a $[\otimes]$. 


\section{La investigación \\ 3.1. Metodología}

La investigación propuesta es de tipo descriptiva y se enmarca dentro de un enfoque metodológico cualitativo (Hernández y Almeida, 2005).

La metodología que se emplea incluye los procedimientos clásicos aplicados al trabajo de campo y análisis fonético-fonológico de los vernáculos chilenos, esto es, en el plano fonético, la discriminación auditiva del material fónico, y, en el plano fonológico, el análisis distribucional de los segmentos (Pike 1947; Burquest 2009).

El marco de referencia teórico-metodológico seguido aquí ha sido de probada pertinencia para la descripción de la fonología de vernáculos en general y del mapudungun hablado en Chile en particular. Esto último se confirma con las descripciones realizadas, entre otros, por Echeverría (1964), Salas (1976), Lagos (1981), Alvarez-Santullano (1986a y 1986b), Salamanca (1997); Salamanca y Quintrileo (2009) y Henríquez y Salamanca (2012 y 2015), etc.

\subsection{Objetivo General}

Determinar la vitalidad de la fonología del mapudungun de los escolares de Tirúa, VIII región del Bío-Bío.

\subsection{Objetivos específicos}

a) Identificar, de acuerdo con el método distribucional, los fonemas segmentales y realizaciones alofónicas del mapudungun de los escolares de la comuna de Tirúa.

b) Identificar las transferencias fonético-fonológicas presentes en la fonología del mapudungun de estos escolares. 
d) Interpretar las transferencias encontradas en términos del grado de vitalidad de la fonología de la lengua.

\subsection{Los participantes}

La muestra es selectiva e intencionada, debido a la ventaja y utilidad que presenta para nuestro diseño de estudio (Hernández y Almeida, 2005). Concretamente, trabajamos con un grupo de 20 escolares mapuches de la comuna de Tirúa, de entre 12 y 15 años de edad, que cursaban 7 u $8^{\circ}$ año básico en dos establecimientos educacionales rurales adscritos al Programa EIB. Todos los colaboradores señalaron conocer el mapudungun en algún grado ${ }^{3}$.

Según lo observado in situ, la mayoría de ellos posee fundamentalmente competencias receptivas $\mathrm{o}$ de comprensión, más que competencias productivas, las que se presentan en menor medida. El conocimiento que los estudiantes tienen de su lengua lo han adquirido principalmente en el ámbito familiar, en sus interacciones cotidianas intracomunitarias, generalmente con los miembros mayores de su familia. Tanto los escolares de Primer Agua como de Ranquilhue reconocen el rol que cumplen sus abuelos en la transmisión de la lengua indígena en sus familias (Henríquez, 2014, 2015).

El impacto que ha tenido la escuela en el desarrollo de la competencia comunicativa en mapudungun de estos niños es menor, pues cuando realizamos el trabajo de campo, estos

\footnotetext{
${ }^{3}$ Concretamente, les aplicamos un cuestionario sociolingüístico en el que les consultamos por su nivel de competencia en mapudungun $\mathrm{y}$, en su mayoría, se autoadscribieron en la categoría "Hablo un poco y entiendo un poco". Además, los directores y educadores tradicionales de cada establecimiento nos señalaron que estos eran los niños más competentes en la lengua indígena.
} 
establecimientos recién estaban iniciando la implementación del subsector de Lengua Indígena en primer y segundo básico, es decir, la enseñanza del mapudungun, a través de la dupla pedagógica profesor mentor y educador tradicional. Este Programa no alcanzó a beneficiar a nuestros entrevistados.

Para la configuración de la muestra se buscó a aquellas escuelas y comunidades que distintos agentes (educadores tradicionales, docentes, directivos, autoridades ancestrales, coordinadores municipales del PEIB, funcionarios de la Corporación Nacional de Desarrollo Indígena (CONADI), etc.) nos señalaron como zonas de mayor retención del vernáculo (donde "más se habla la lengua"). El trabajo de campo contempló varias visitas de acercamiento a las diferentes escuelas y comunidades, y más tarde, luego de seleccionar a los colaboradores, se llevó a cabo la etapa de recogida de datos en las localidades de Primer Agua y Ranquilhue.

\subsection{Estrategias para la recolección del material}

Para la elicitación del corpus fonético-fonológico se utilizaron las siguientes estrategias:

a) Una lista léxica ${ }^{4}$ de 65 ítems, compuesta de palabras relativas al mundo inmediato y circundante del niño, tales como partes del cuerpo, alimentos, términos de parentesco, flora, fauna, colores, numerales, etc. Al seleccionar la lista de palabras tuvimos especial cuidado en incluir todos los fonemas de la lengua mapuche, especialmente aquellos que no están presentes en el patrón fonológico del español de Chile, tales como: /ü, t $, n_{n}, \underset{n}{1}, \underset{C}{C}, \Delta, \times, \mathrm{N}, \square$ (tr)/ o que están

\footnotetext{
${ }^{4}$ La lista léxica fue sometida a juicio de dos expertos y revisada por dos hablantes de mapudungun.
} 
presentes, pero con una distribución fonotáctica distinta, como es el caso de /)/.

b) Además, se aplicó la narración oral de una historia breve que tuvo por objeto complementar los datos fonéticofonológicos obtenidos a través de la lista léxica. En términos generales, diseñamos y presentamos a los niños un relato breve en mapudungun, que contenía palabras seleccionas ${ }^{5}$ de la lista léxica. Luego de escuchar la grabación en dos oportunidades, los niños debían narrar la historia en mapudungun o contar lo que recordaban de ella. El texto de la historia fue revisado, corregido y grabado por dos colaboradores mapuche hablantes.

\section{Resultados}

\subsection{Consideraciones previas}

4.1.1. Diferenciamos en este análisis entre palabras respondidas y palabras expectables o consultadas. Las primeras, son aquellas tanto de la lista léxica como del cuento, que los escolares conocen y responden ante la consulta del investigador; difieren de colaborador en colaborador, pues dependen del manejo del vocabulario que posee cada participante. Las palabras expectables, en cambio, corresponden al total de ítems consultados tanto de la lista léxica como del cuento y que, por lo tanto, es teóricamente expectable su ocurrencia. Para efectos de este análisis, consideraremos fundamentalmente las palabras respondidas por los colaboradores.

4.1.2 En esta presentación diferenciamos entre fluctuación de fonemas y alternancia de fonemas. El primero es un fenómeno característico y generalizado del mapudungun, en

\footnotetext{
${ }^{5}$ Estas palabras fueron seleccionadas de la lista léxica por los segmentos que contenían, específicamente fonemas del mapudungun ausentes en el inventario del español.
} 
el que el mismo hablante opta libremente por el uso de un fonema u otro en la misma unidad léxica (Salas, 1992). La alternancia de fonemas, en cambio, se da solo en algunos hablantes de la misma comunidad y estaría motivada por diversos factores, tales como la transferencia fonológica, el grado de bilingüismo, etcétera.

4.1.3 Los casos que se considerarán como indicadores de vitalidad del vernáculo son dos: a) la ocurrencia del fonema vocálico /a/ y consonánticos /tt , n, $\underset{n}{1}$, f, ð, $K, \mathrm{y}, \mathrm{ts} / \mathrm{y}$ b) la ocurrencia del fonema $/ \mathrm{n} /$ en el postmargen silábico.

A continuación se presenta el análisis de los segmentos vocálicos y consonánticos en ambas zonas de estudio.

\subsection{Vocales}

De acuerdo con los procedimientos aplicados, el inventario vocálico del mapudungun que manejan los escolares de Primer Agua y Ranquilhue está compuesto por cinco fonemas segmentales: /i, e, a, o, u/. En este inventario está ausente la denominada "sexta vocal", único fonema vocálico del mapudungun que no se encuentra en el sistema fonológico del castellano, por lo que su ausencia resulta altamente relevante al momento de indagar en la vitalidad del sistema fonológico mapuche en esta zona de contacto, en que el castellano es la lengua dominante o primaria de los niños ${ }^{6}$.

\footnotetext{
${ }^{6}$ Según información obtenida a través del cuestionario y de las entrevistas sociolingüísticas aplicadas a los escolares y a los educadores tradicionales de ambas escuelas, el castellano es la lengua dominante en los procesos de comunicación intracomunitarios en los que participan los niños. El mapudungun queda relegado, principalmente, a conversaciones familiares entre ancianos, a eventos ceremoniales y protocolares de la comunidad (Henríquez, 2014 y 2015).
} 
Según el corpus analizado, hemos podido constatar la ocurrencia residual de las dos variantes vernáculas de este segmento: el fono alto posterior no redondeado [u] y el central medio no redondeado [ə]. El desempeño de estas variantes es el siguiente.

Tabla 1. Realizaciones de /w/

\begin{tabular}{|l|c|c|}
\hline $\begin{array}{l}\text { \% de realización de } \\
\text { /u/ en palabras } \\
\text { respondidas }\end{array}$ & Primer Agua & Ranquilhue \\
\cline { 2 - 3 } & 8,8 & 10,8 \\
\hline
\end{tabular}

En Primer Agua, ocurre sólo el fono [u], que alcanza un $8,89 \%$ de ocurrencias en las palabras respondidas. En Ranquilhue, ambos fonos ([u]/[ə]) representan un total de $10,8 \%$. Estos porcentajes de ocurrencia se explican por los siguientes factores:

a) En los ítemes efectivamente respondidos, en los que se esperaba la ocurrencia de alguna de las dos variantes vernáculas, éstas fueron mayoritariamente sustituidas por los fonos [u] e [i] en más de un $90 \%$.

b) En las escasas palabras donde sí ocurrió alguna de las variantes tradicionales, éstas aparecen en alternancia con los fonos $[\mathrm{u}] \mathrm{o}[\mathrm{i}]$.

c) Existe un significativo número de ítemes no respondidos por los escolares, en los que era expectable la ocurrencia de alguna de las dos variantes.

Como ya se señaló, cuando el fonema /u/ no ocurre es porque ha sido reemplazado por el fono $[\mathrm{u}]$, alto posterior redondeado, o por el fono [i], alto anterior no redondeado. 
En Primer Agua, los fonos de reemplazo [u] e [i] representan el $68,8 \%$ y $22,2 \%$ de las realizaciones, respectivamente; y en conjunto alcanzan un $91,1 \%$. En tanto que en Ranquilhue, las realizaciones no vernáculas representan el 89,1\%: el fono [u] registra un 71,7\% y el fono [i] un $17,3 \%$.

Si consideramos ambas zonas, el reemplazo de /u/ se da en un $90 \%$ de los contextos respondidos, siendo la sustitución de /u/ por /u/, por lejos, la más recurrente entre los niños. La vocal alta posterior / $\mathrm{u} /$ presenta un total de nueve ocurrencias, ocho corresponden a la variante $[\mathrm{u}]$ y una a la variante [ə]. La primera, en alternancia con [i] y con [u]; la segunda, en alternancia con [u]. De los 20 escolares que componen esta muestra, ninguno la produce de manera consistente; siete de ellos, la registró en una o dos ocasiones. Además, de las 35 palabras elicitadas, en que era expectable su ocurrencia, se observó sólo en una en Primer Agua y en cuatro, en Ranquilhue; es decir, en la mayoría de las palabras respondidas fue sustituida por $[\mathrm{u}]$ o por [i].

Los siguientes son ejemplos de alternancia y de reemplazo en Primer Agua y Ranquilhue.

Alternancia /u/ /u/ e /i/ en Primer Agua:

(1) /kula/ / kula/ "tres"

(2) $/$ kula/ /kila/ "tres"

Alternancia /u/ /u/ en Ranquilhue:

(3) /antu/ /antu/ "día, sol"

(4) /wunn/ /gun/ "boca"

(5) /kutssal/ /kutșal/ "fuego" 
Reemplazo de /u/ por /u/ y/u/ por/i/ en Primer Agua y Ranquilhue:

(1) /antu/ por /antu/ "día (2) /tumn/ por/tun/ "piojo"

(3) /punum/ por /punun/ "pene (4) /kula/ por / kula/ "tres"

(5) /kula/ por /kila/ "tres"

En resumen, dado que este fonema no está presente en el inventario de vocales del castellano, era teóricamente plausible la ocurrencia de instancias de sustitución o alternancia fonológica y, efectivamente, los datos corroboran este hecho, pues se evidencia un avanzado proceso de transferencia que ha provocado la pérdida de estatus fonémico de este segmento en ambas localidades en estudio. De este modo, el sistema vocálico mapuche de la zona queda reducido a 5 vocales.

\subsection{Consonantes}

\subsubsection{Nasal palatal /n/ en postmargen silábico}

Este fonema presenta un único alófono vernáculo: el nasal palatal sonoro [n], cuya ocurrencia en posición final de sílaba resulta relevante para medir su vitalidad, debido a que no ocurre, en este contexto, en castellano; por esta razón, es teóricamente posible un proceso de desestabilización por contacto, en esta posición.

A continuación se presenta el rendimiento de este fonema en el postmargen silábico.

Tabla 2. Realizaciones del fonema $/ \mathrm{n} /(\ldots$ \#)

\begin{tabular}{|c|c|c|}
\hline $\begin{array}{l}\% \text { de } \\
\text { / realización de } \\
/ \mathrm{y} \text { en } \\
\text { resnondidas }\end{array}$ & Primer Agua & Ranquilhue \\
\hline respondidas & 6,6 & 11,1 \\
\hline
\end{tabular}


Esta baja frecuencia de uso se explica por el alto índice de sustitución que afecta al segmento en esta posición y por las escasas palabras respondidas. El reemplazo por otra consonante nasal alcanza, en ambos sectores, el $91 \%$ de los contextos realizados.

Cuando la variante vernácula no ocurre, es porque ha sido reemplazada por alguno de los siguientes fonos: nasal alveolar sonoro [n]; nasal velar sonoro [y] o nasal bilabial sonoro $[\mathrm{m}]$. El detalle de las realizaciones de estas variantes es el siguiente:

- La nasal [n] registra un 26,6\% en Primer Agua y un $33,3 \%$ en Ranquilhue.

- La nasal [y] presenta un 66,6\% en primer Agua y un $44,4 \%$ en Ranquilhue.

- La nasal [m] ocurre sólo en Ranquilhue y alcanza un $11,1 \%$.

Ejemplos de reemplazo de $/ \mathrm{n} /$ por $/ \mathrm{n} / \mathrm{y} / \mathrm{y} /$ en Primer Agua y Ranquilhue:

(1) /me.tkej/ por /merken/ "ají molido"

(2) /me.jkej/ por /merkey/ "ají molido"

(3) /sanwe/ por /saywe/ "cerdo"

Ejemplos de reemplazo de / $\mathrm{n} /$ por $/ \mathrm{m} /$ en Ranquilhue:

(4) /mezkej/ por /merkem/ "ají molido"

Aunque el reemplazo del fonema es lo más característico en la zona, también se observó la alternancia de /y/ /y/: (5) /sanwe/ /saywe/ "cerdo".

La tendencia a la alternancia y, principalmente, al reemplazo parece motivada por el contacto con el castellano, 
y se trataría de un proceso de transferencia desde esta lengua al mapudungun ${ }^{7}$. Lo que sucede en este caso, es que los niños de Tirúa reproducen el fonema del sistema secundario (mapudungun) de acuerdo con las reglas fonéticas de la lengua dominante, lo que explicaría la tendencia hacia la despalatalización de /n/ en posición final. En la literatura especializada, esta transferencia se conoce como reinterpretación del sistema (Weinreich, 1974; Sala, 1988) ${ }^{8}$.

\subsubsection{Nasal velar /y/}

El fonema nasal velar, que posee dos variantes tradicionales (nasal postpalatal $\left[\mathrm{\eta}^{\mathrm{j}}\right]$ y nasal velar $[\mathrm{y}]$ ), presenta el siguiente comportamiento en Tirúa:

Tabla 3. Realizaciones del fonema $/ \mathrm{l} /$

\begin{tabular}{|l|c|c|}
\hline \multirow{2}{*}{$\begin{array}{l}\text { \% de realización de } / \mathbf{y} / \text { en } \\
\text { palabras respondidas }\end{array}$} & Primer Agua & Ranquilhue \\
\cline { 2 - 3 } & 15,3 & 8,5 \\
\hline
\end{tabular}

En Primer Agua, se registran sólo cuatro ocurrencias, de 26 instancias respondidas, las que representan el 15,3\% de las realizaciones. En Ranquilhue, se constatan sólo tres ocurrencias, de 35 contextos respondidos, las que equivalen al 8,5\%. Estas siete ocurrencias son realizadas por siete de nuestros 20 colaboradores. La explicación de esta baja frecuencia es la misma que se ha señalado más arriba para los

\footnotetext{
${ }^{7}$ Esta transferencia también ha sido reportada en la Araucanía, en jóvenes bilingües de la Provincia de Cautín (Henríquez, 2004) y en hablantes mapuches al este de los Andes, especialmente en el dialecto ranquel (Malvestitti, Fernández y Díaz-Fernández, 2009).

${ }^{8}$ Según el esquema de Van Coetsem (1988), los hablantes que poseen menor competencia en su segunda lengua imponen rasgos de la lengua en la que poseen mayor dominio o competencia. De acuerdo con este autor, esta innovación se trataría de una transferencia por imposición.
} 
otros segmentos en análisis: significativo reemplazo del fonema por influencia de la lengua dominante y niveles mínimos de competencia léxica de los colaboradores de ambas comunidades.

Los datos de ambas zonas muestran que la vitalidad de este fonema está seriamente comprometido producto del sistemático proceso de reemplazo que lo afecta.

Entre las variantes de reemplazo del fonema nasal velar /y/ encontramos las siguientes:

(1) [n] nasal alveolar sonora (2) [n] nasal palatal sonora (3) $\left[\mathrm{\gamma}^{\mathrm{j}}\right]$ fricativa postpalatal sonora $(4)\left[\mathrm{g}^{\mathrm{j}}\right]$ oclusiva postpalatal sonora (5) [b] oclusiva bilabial sonora (6) [v] fricativa labiodental sonora (7) [i] alta anterior no redondeada y (8) [u] alta posterior redondeada.

En el siguiente cuadro se presentan los porcentajes de realización de cada una de estas variantes de reemplazo, en aquellas palabras respondidas en que era expectable el uso de la variante vernácula.

Tabla 4. Variantes de reemplazo de /y/en Primer Agua y Ranquilhue

\begin{tabular}{|l|c|c|c|c|c|c|c|c|}
\hline $\begin{array}{l}\text { Variantes de } \\
\text { Reemplazo }\end{array}$ & {$[\mathrm{n}]$} & {$[\mathrm{n}]$} & {$\left[\mathrm{\gamma}^{\mathrm{j}}\right]$} & {$\left[\mathrm{g}^{\mathrm{j}}\right]$} & {$[\mathrm{b}]$} & {$[\mathrm{v}]$} & {$[\mathrm{i}]$} & {$[\mathrm{u}]$} \\
\hline \% Primer Agua & --- & 11,5 & 23,0 & 11,5 & 3,8 & 3,8 & 26,9 & --- \\
\hline \% Ranquilhue & 8,5 & 25,7 & 14,2 & 25,7 & 2,8 & --- & 2,8 & 11,4 \\
\hline
\end{tabular}

Como se observa, las realizaciones de reemplazo son variadas y ampliamente predominantes: en Primer Agua se registran seis tipos diferentes, mientras que en Ranquilhue, siete. La ocurrencia de estas variantes, en detrimento del 
fonema vernáculo, alcanza un 80,7\% en Primer Agua y un 91\% en Ranquilhue, es decir, superan largamente el porcentaje de ocurrencia del fonema $/ \mathbf{y} /$.

Además de las instancias de remplazo, se observó, en una ocasión, la supresión o elisión de este fonema en Primer Agua, cuando un escolar, al ser consultado por la palabra "hermana" (/lamnen/), responde [la'men].

Ejemplos de reemplazo de /y/ por /y/, /g/, /b/ y /v/:

(1) /yiKatun/ por /yijatun/ "rogativa mapuche"

(2) /niKatun/ por /gijatun/ "rogativa mapuche"

(3) /niKatun/ por /vijatun/ "rogativa mapuche"

(4) /niKatun/ por /bijatun/ "rogativa mapuche"

Reemplazo de /y/ por /i/ y /u/:

(5) /lampen/ por /lamien/ "hermana"

(6) /lamyen/ por /lamuen/ "herman

La ocurrencia de estas variantes de reemplazo del fonema $/ \mathbf{y} /$ se puede explicar tanto por la influencia del castellano (es decir, por transferencia de rasgos), como por vacilaciones o inseguridad en la elección de fonos por conocimiento deficitario o incompleto del sistema fonológico del chedungun ${ }^{9}$. El influjo ejercido por la lengua dominante es evidente, pues la tendencia es en favor de fonos/fonemas propios del español, como ocurre con los fonos de reemplazo oclusivos, fricativos, nasales y velares que se encuentran en

\footnotetext{
${ }^{9}$ Para Salas, la alta ocurrencia de fluctuación de fonemas que se da en el dialecto huilliche, entre sonidos que no tienen entre sí mayor similitud fonética, es producto del conocimiento lingüístico individual imperfecto y disminuido, y de las interferencias de la lengua dominante (1992:91-91).
} 
el sistema de la lengua dominante; o como sucede con la vocalización de $/ \mathrm{y} / \mathrm{en} / \mathrm{u} / \mathrm{o} / \mathrm{i} /{ }^{10}$.

\subsubsection{Lateral palatal $/ \times /$}

Según los datos obtenidos en Tirúa, el fonema $/ x /$ no forma parte del inventario fonológico del mapudungun de los escolares de la zona. Esto, porque no se registró ninguna realización de la lateral palatal $/ \times /$ en los escolares de Primer Agua y Ranquilhue (en las escasas palabras realizadas en las cuales era expectable su ocurrencia, fue reemplazada sistemáticamente por otro fonema).

En Primer Agua, en las doce realizaciones en las que se esperaba la ocurrencia de $/ \times /$, fue sustituida en un $92 \%$ por el fonema aproximante palatal sonoro $/ \mathrm{j} /$, y en un $8 \%$ por el fonema lateral alveolar sonoro /1/. En Ranquilhue, la situación es similar, ya que en las doce realizaciones efectuadas por los niños fue reemplazada en un $100 \%$ por $/ \mathrm{j} /$.

Es importante consignar que, al igual que en los casos anteriores, los estudiantes no responden la mayoría de los ítemes consultados en los que era expectable la realización del fonema $/ x /$. En Primer Agua, las instancias no respondidas ascienden al 90\%, mientras que en Ranquilhue alcanzan el $87 \%$.

10 El fenómeno de la vocalización también lo hemos observado en Alto Bío-Bío, donde se han encontrado algunas alternancias de este fonema con la vocal /i/, aunque a diferencia de Tirúa, no se trata de reemplazos, sino de alternancias, que resultan muy poco significativas si consideramos el alto índice de vitalidad que presenta este fonema en esa zona (Henríquez, 2013; Henríquez y Salamanca, 2015). 
En Primer Agua, los únicos dos ítems con este segmento que responden los escolares fueron "rogativa

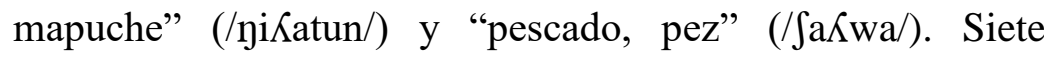
escolares conocen la palabra /yiKatun/ y todos ellos reemplazan el fonema $/ K /$ por el aproximante palatal $/ \mathrm{j} /$. Para el caso de $\left(/ \int \mathrm{a} \kappa \mathrm{wa} /\right)$, el único estudiante que conoce la palabra la realiza como ['Salwa]. Lo mismo sucede en Ranquilhue, donde "rogativa mapuche" (/yi Katun/) es el único ítem que conocen y responden los niños e, igualmente, todos lo realizan con la aproximante palatal /j/. Frente al resto de las palabras consultadas para la elicitación del fonema, los escolares no responden, porque no conocen el ítem o no lo recuerdan.

Dado que este fonema no está presente en el inventario de consonantes del castellano, era factible prever instancias de sustitución o alternancia por otro(s) fono(s) o fonema(s) existente(s) en el castellano, o que comparten ambos sistemas. Esto, efectivamente, sucedió: el fonema $/ \times /$ fue reemplazado por los fonos palatal sonoro [j] y lateral sonoro [1] en todas las instancias realizadas por los niños. Es decir, se produjo su castellanización.

Este fenómeno de transferencia ha impactado en la matriz fonológica mapuche, provocando una reorganización de este sistema, producto del desplazamiento de $/ \times /$. Debido a esto, la serie palatal mapuche quedó reducida a los fonemas /n, j/, en lugar de los tradicionales /n, $\times, \mathrm{j} /$. Esta pérdida de fonema es una evidencia más del proceso de convergencia fonológica hacia el castellano que muestra el sistema fonológico del mapudungun de estos niños. 


\subsection{4 (Inter) Dentales /t, n,,$\underset{n}{\mathrm{n}} /$}

Como hemos dicho en apartados precedentes, debido a la ausencia de los fonemas (inter)dentales $/ t, n, n, 1 /$ en el inventario de fonemas del castellano, es factible hipotetizar algún grado de desestabilización de estos segmentos, por influencia de la lengua dominante. En efecto, los datos recogidos en ambos sectores muestran el proceso de desfonologización que afecta a estos fonemas.

\subsubsection{Oclusiva interdental / $t /$}

Según nuestro corpus, este segmento no está presente en el inventario de fonemas que presentan los colaboradores de Tirúa, ya que en ambas localidades ha sido sustituido por el fonema oclusivo alveolar / $t /$, en el total de las emisiones realizadas por los niños.

En Primer Agua, en las dieciocho instancias realizadas, fue reemplazada por el fonema oclusivo alveolar /t/. Esta misma situación se repite en Ranquilhue: en las 17 realizaciones en que se esperaba su ocurrencia, fue reemplazada por el fono $[\mathrm{t}]$.

Este proceso de sustitución se observa en los siguientes ejemplos:

(1) /antu// por /antu/ "sol, día"

(2) $/$ tuun/ por /tun/ "piojo"

(3) $/$ tol $/$ por $/$ tol/ "frente"

(4) /topel// por /topel/ "nuca"

En definitiva, según nuestro corpus, el segmento interdental oclusivo / $/ \mathrm{t} / \mathrm{ha}$ perdido su estatus de fonema en ambos sectores. 


\subsubsection{Lateral interdental ///}

En general, la situación de este fonema es similar a lo que acontece con la oclusiva interdental, pero presenta algunas particularidades que conviene precisar.

Al analizar las palabras respondidas en Primer Agua, constatamos que la variante vernácula lateral interdental [1] presenta un $0 \%$ de realizaciones. Es decir, en los 4 casos realizados en que era expectable su ocurrencia, fue reemplazada por la variante lateral alveolar [1]. Así, de los ocho ítems consultados, cuatro estudiantes de este sector sólo conocen la palabra "quila" (/kula/), la cual realizan siempre como [' $\mathrm{k}^{\mathrm{j}} \mathrm{ila}$ ].

En Ranquilhue, en cambio, este fono alcanza un $18,75 \%$ en las palabras respondidas. Este porcentaje representa a escasas tres ocurrencias, de 16 instancias realizadas. La realización de reemplazo, lateral alveolar [1], asciende al $81,2 \%$ restante. Se agrega a esto que sólo un informante del sector realiza esta variante (siempre en alternancia con el fono alveolar). Así, cuando es consultado por la palabra "cuello o cogote" (/pel/), responde [pel] y [pel]; lo mismo sucede cuando es consultado por "frente" (/tol/), la cual realiza como [toll] y [tol].

Los datos con que contamos nos permiten postular que la distinción entre lateral interdental y lateral alveolar no es consistente en Ranquilhue, pues, el fonema originario sólo presenta escasas tres ocurrencias, realizadas por un solo hablante, en dos de las ocho palabras elicitadas. 
Ejemplos de reemplazo de / / / por /// en Primer Agua y Ranquilhue:
(1) $/$ toll $/ /$ por $/$ tol/
"frente"
(2) $/$ pel $/$ por $/$ pel/
"cuello, cogote"
(3) $/$ kula $/$ por $/ \mathrm{kila} /$
"quila"

Ejemplos de alternancia de $/ 1 / / / 1 /$ en Ranquilhue:
(1) $/ \mathrm{pel} / \sim$ /pel/
"cuello, cogote"
(2) $/$ tol $/ \sim$ $/$ tol $/$
"frente"

\subsubsection{Nasal interdental /n/}

En Primer Agua, al igual como sucedió con las otras dos interdentales, la nasal interdental $/ \mathrm{n} /$ no se observa en ninguna de las palabras respondidas. En las 26 instancias realizadas por los escolares fue reemplazada por el fonema nasal alveolar/n/. En Ranquilhue, la situación no es diferente, aunque se debe destacar la ocurrencia de tres escasas realizaciones del fono nasal interdental, las que representan el $8,8 \%$ del total de realizaciones; por el contrario, la variante de reemplazo nasal alveolar [n] se eleva a un $91,1 \%$. Es decir, el fonema originario es ampliamente sustituido por su contraparte nasal alveolar. Las tres ocurrencias de [n] resultan de un total de 34 realizaciones y están en alternancia con [n] en las tres oportunidades. Así, tenemos el caso de un niño que al ser consultado por la palabra "pie, pata" (/namun/) responde ['namu] ['namu] [na'mun] [na'mun] [na'mun] y [na'mun]. Así también, otro escolar realiza la palabra "boca, hocico" (/wun/) como [wun] y [wun]. Estas escasas apariciones, reflejan el estado crítico del fono vernáculo en la zona.

Por otra parte, en Primer Agua, se dio el caso de un niño que reemplazó la variante interdental [n] no sólo por el 
sonido alveolar [n], sino también por el sonido nasal velar [y]. Así, cuando se le pregunta por la palabra "pie, pata" (/namun/), responde [na'muy] [na'mun] y [na'mun] ${ }^{11}$.

Al igual que lo ocurrido con los otros segmentos en análisis, la mayoría de los ítemes consultados para la elicitación de este fonema eran ignorados por los niños.

Ejemplos de reemplazo de $/ n /$ por $/ \mathrm{n} /$ en Primer Agua $\mathrm{y}$ Ranquilhue:
(1) /namun/ por /namun/ "pie, pata"
(2) /wun/ por /wun/ "boca"
(3) /antu/ por /antu/ "sol, día"
(4) $/$ tuun/ por /tun/ "piojo"
(5) /punum/ por /punun/ "pene"

Ejemplos de alternancia $/ \mathrm{n} / \sim / \mathrm{n} /$ en Ranquilhue:

(1) /wun/ $\sim$ /wun/ "boca"
(2) /namun/ $/$ /namun/ "pie, pata"

La siguiente tabla caracteriza la situación de las tres (inter)dentales en el área.

\footnotetext{
${ }^{11}$ Estos ejemplos, al igual que muchos otros observados entre los niños, muestran las dudas y vacilaciones que presentan en la elección de la variable fonológica, lo que estaría motivado por desconocimiento de las formas tradicionales, debido a la falta de competencia en el vernáculo y por la preeminencia de la lengua castellana en su desempeño lingüísticocomunicativo.
} 
Tabla 5. Realizaciones de los fonemas $/ t, n, l /$

\begin{tabular}{|l|c|c|c|}
\hline $\begin{array}{l}\text { \% de realización en } \\
\text { palabras Respondidas }\end{array}$ & $/ \mathrm{t} /$ & $/ \mathrm{n} /$ & $/ \mathrm{l} /$ \\
\hline Primer Agua & 0 & 0 & 0 \\
\hline Ranquilhue & 0 & 8,8 & 18,7 \\
\hline
\end{tabular}

En resumen, los escolares de Primer Agua y Ranquilhue subdiferencian las interdentales y alveolares en favor de las alveolares. Esta falta de diferenciación llega incluso a la desfonologización, pues en ambos sectores las interdentales han perdido su estatus de fonema. En esto, coincidimos con Salamanca y Quintrileo (2009) quienes, en su descripción del mapuche de la zona, señalan que estos fonos interdentales no se presentan como fonemas distintivos sino como variantes de los sonidos alveolares.

\subsubsection{Fricativa interdental /ð/}

En Primer Agua, el fonema /ð/ se presenta como el más vital de los segmentos analizados. En las palabras respondidas, alcanza un $100 \%$ de ocurrencia, pues está presente en los ocho casos realizados por los escolares. Se trata de ocho informantes que realizan la palabra "montaña" (/mawiða/) siempre como [ma'wiða]. Sin embargo, esta situación de alta vitalidad se relativiza, si el análisis se efectúa desde la perspectiva del total de palabras consultadas o expectables, ya que este porcentaje desciende a un $12,12 \%$, debido al limitado número de palabras consultadas que conocen los niños.

En Ranquilhue, la situación es más compleja, pues no se registró ninguna ocurrencia del fonema. Esta ausencia no se debe a su reemplazo, sino al hecho de que los escolares no conocen ninguna de las palabras, tanto de la lista léxica como 
del cuento, en las que era expectable la ocurrencia del fonema.

Entre los ítemes consultados y que los estudiantes desconocen se cuentan: (1) "mujer" (/ðomo/), (2) "sal"

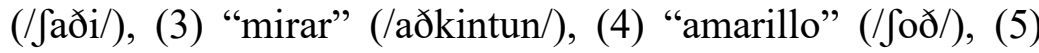
"montaña (/mawiða/) y (6) "ombligo" (/vuðo/). Pensábamos que estas palabras, de uso general y cotidiano, serían de dominio de los escolares; pero no fue así. Con el propósito de elicitar el segmento, además de la aplicación de la lista léxica y del cuento, se les consultó a los niños por otras palabras que fueran de su dominio: animales domésticos, pájaros, alimentos, pero incluso en esos casos adicionales el segmento en estudio no se observó.

Esta situación no permite postular la ausencia del fonema en la zona, porque una indagación focalizada, que por cierto no era el propósito de esta investigación, podría constatar su ocurrencia. Pero consideramos relevante consignar el estado de inestabilidad en que se encuentra, pues es el único segmento que no se reporta por ausencia de ítemes respondidos. Esto constituye una evidencia más del limitado manejo léxico que presentan los colaboradores del sector.

Las ocho realizaciones vernáculas encontradas en Primer Agua (100\%) corresponden al alófono fricativo interdental sonora [ð]. No se observaron realizaciones de la variante fricativa interdental áfona $[\theta]$.

En conclusión, no se observan situaciones de alternancia ni de reemplazo del fonema en Primer Agua, ya que su rendimiento es de un $100 \%$, aunque como ya se señaló, ocurre sólo un ítem respondido. En Ranquilhue, por su parte, la ausencia de datos impide postular el estatus del 
segmento y sostener cualquier hipótesis de transferencia por contacto $^{12}$.

\subsubsection{Aproximante retrofleja /.t - Fricativa retrofleja /Z̨/}

En Primer Agua, el fonema aproximante retroflejo / $/$ presenta baja frecuencia, con un $23 \%$ del total de ocurrencias en las palabras respondidas. El corpus analizado muestra que de las 26 instancias realizadas, sólo 6 corresponden a una de las dos variantes vernáculas que presenta el fonema en el sector: por una parte, el alófono aproximante retroflejo [t], que alcanza un $15 \%$ de realizaciones (razón por la cual lo hemos escogido como la forma básica del fonema); y, por otra parte, el alófono fricativo retroflejo [z], que representa el $8 \%$.

En Ranquilhue, nuestros datos también corroboran la existencia de dos variantes vernáculas: [z] y [.], pero en este sector es el alófono fricativo retroflejo [z] el que reporta un mayor número de ocurrencias (por consiguiente, lo hemos relevado como el representante del fonema). En las palabras respondidas, este fonema /z/, a través de sus dos variantes, presenta 9 de 24 realizaciones, lo que representa el 37,5\%. Estas ocurrencias se desglosan de la siguiente manera: [z], representa el $25 \%$, y [.] , el $12,5 \%$ restante. Los datos muestran que el rendimiento de este fonema es mayor en Ranquilhue que en Primer Agua.

\footnotetext{
12 En Alto Bío-Bío, nuestros datos muestran que este segmento es el que presenta menores índices de frecuencia, después de las (inter)dentales $/ \mathrm{t}$, n, 1/, producto de las transferencias del castellano (Henríquez, 2013).
} 
En ambos sectores, las instancias no respondidas alcanzan porcentajes altamente significativos: $81,4 \%$ en Primer Agua y 80,9\% en Ranquilhue. En el siguiente cuadro se resume esta situación del fonema.

Tabla 6. Realizaciones del fonema / $\downarrow /$ o /

\begin{tabular}{|l|c|c|}
\hline \multirow{2}{*}{$\begin{array}{l}\text { \% de realización de } / \mathfrak{l} /-/ Z_{6} / \\
\text { en palabras respondidas }\end{array}$} & Primer Agua & Ranquilhue \\
\cline { 2 - 3 } & 23 & 37,5 \\
\hline
\end{tabular}

Cuando el segmento originario /z / o / / no ocurre es porque ha sido sustituido por otro sonido. Los datos muestran la existencia de tres variantes no vernáculas del fonema, las que ocurren tanto en Primer Agua como en Ranquilhue: (1) [r] vibrante simple alveolar sonora; (2) [r] vibrante múltiple alveolar sonora; (3) [dz] africada retrofleja sonora.

En la siguiente tabla se presentan los porcentajes de realización de cada una de estas variantes de reemplazo en aquellas palabras consultadas en las que era expectable la ocurrencia de alguno de los dos fonos vernáculos.

Tabla 7. Variantes de reemplazo de $\mid \mathfrak{\jmath} /-/ z_{6} /$

\begin{tabular}{|l|c|c|c|}
\hline $\begin{array}{l}\text { \% Variantes de } \\
\text { reemplazo }\end{array}$ & {$[\mathrm{r}]$} & {$[\mathrm{r}]$} & {$[\mathrm{dz}]$} \\
\hline Primer Agua & 19,2 & 30,7 & 26,9 \\
\hline Ranquilhue & 16,6 & 37,5 & 8,3 \\
\hline
\end{tabular}


Si comparamos los porcentajes de realización de estas variantes emergentes con los alcanzados por las variantes vernáculas, resulta evidente la preeminencia de las primeras en la zona. Efectivamente, las variantes de reemplazo son, en conjunto, ampliamente predominantes, alcanzando en Primer Agua un $76,9 \%$ y un $62,5 \%$ en Ranquilhue.

Además de las instancias de reemplazo, se observaron, aunque escasamente, situaciones de alternancia que involucran tanto a la vibrante múltiple [r], como a la africada retrofleja sonora [dz], las cuales no sólo alternan entre sí, sino también con alguna de las dos variantes vernáculas.

Los siguientes ejemplos muestran estos procesos de reemplazo y alternancia.

Ejemplos de reemplazo de /x/ por /r/, /s/ y [dz] en Primer Agua:

(1) /reyle/ por ['dzeyle] "siete"

(2) / feyle/ por /regle/ "siete"

(3) /maji/l por /mari/ "diez"

(4) $/$ kuðu/ por /kuri/ "negro"

Ejemplos de reemplazo de /z/ por/r/, /s/ y [dz] en Ranquilhue:

(1) /zeyle/ por /reyle/ "siete"

(2) /zeyle/ por [dzeyle] "siete"

(3) /mazil/ por /mari/ "diez"

(4) /mezkej/ por /merken/ "ají molido"

Ejemplos de alternancia $/ \mathrm{d} /\left(/ \mathrm{z}_{\mathrm{l}} /\right) \sim / \mathrm{r} /, / \mathrm{r} / \mathrm{y}$ [dz] en Primer Agua y Ranquilhue:

(1) /zeyle/ /reyle/ "siete"

(2) /zeyle/ [dzeyle] "siete" 
(3) $/$ feyle/ [dzeyle] "siete"
$(4) /$ maji $/$ /mari/ "diez"
$(5) /$ mazil $\sim$ /mari/ "diez"

La ocurrencia de la vibrante múltiple [r] y de la vibrante simple [r], en reemplazo de la aproximante retrofleja o fricativa retrofleja, revela el proceso de transferencia que afecta al sistema fonológico mapuche de estos niños por influjo de la lengua dominante. Ambos son fonos/fonemas del castellano ausentes en el inventario de fonos/fonemas del mapudungun. Su ocurrencia es significativa en la zona, por ello les hemos dado el estatus de variantes del fonema vernáculo /£/ o /zl.

El fono africado retroflejo sonoro [dz] también es emergente en estos sistemas fonológicos, pues no forma parte de las descripciones tradicionales de la lengua mapuche en general ni de las específicas de este dialecto. Por lo mismo, es posible que su ocurrencia esté motivada por el contacto interlingüístico, pero no tenemos los antecedentes suficientes para postular dicha transferencia, pues carecemos de estudios descriptivos específicos de la fonología del castellano de la zona $^{13}$.

En resumen, todos estos antecedentes nos permiten sostener el estado de alta inestabilidad del segmento vernáculo en la zona.

\footnotetext{
${ }^{13}$ En Alto Bío-Bío, también se reportaron algunas realizaciones de este fono emergente [dz], concretamente en la comunidad de Cauñicu, no así en Butalelbun, donde los fonemas vernáculos ostentan gran vitalidad (Henríquez, 2013; Henríquez y Salamanca, 2015)
} 


\subsubsection{Africada retrofleja /ts/}

El análisis de nuestro corpus revela que el fonema africado retroflejo presenta gran inestabilidad en Primer Agua, pues alcanza sólo un 16\%. Este porcentaje está dado por escasas cuatro ocurrencias, de 25 realizaciones totales. Esta baja ocurrencia se explicaría, como ha sido una constante en la zona, por las situaciones de reemplazo y por desconocimiento de la mayoría de los ítemes consultados. Concretamente, de las 10 palabras consultadas, los escolares sólo conocen dos: "perro" (/tsewa/) y "ají" (/tsapi/), las que realizan mayoritariamente sin el fono vernáculo.

En Ranquilhue, la situación es un tanto diferente, porque el fonema alcanza un 53,57\% de ocurrencia. Es decir, de los 28 casos realizados, 15 se presentan con el fono [ts], lo que es bastante superior a las cuatro realizaciones de Primer Agua.

Tabla 8. Realizaciones del fonema /ts/

\begin{tabular}{|l|c|c|}
\hline \multirow{2}{*}{$\begin{array}{l}\text { \% de realización de /ts/ en } \\
\text { palabras respondidas }\end{array}$} & Primer Agua & Ranquilhue \\
\cline { 2 - 3 } & 16 & 53,5 \\
\hline
\end{tabular}

Como se observa, el fonema africado retroflejo, a través de su realización vernácula [ts], muestra bajos índices de vitalidad, especialmente en Primer Agua, donde es ampliamente superado por la realización de reemplazo $[t+r]$. Ésta, es el resultado de la suma de un fono oclusivo alveolar [t] más un fono vibrante simple [r]. Evidentemente, se trata de una realización castellanizada del fono originario [ts]. Los 
escolares descomponen el fonema $/ \mathrm{ts} /$ en $[\mathrm{t}+\mathrm{r}]$, es decir, reproducen el sonido mapuche con referencia al sistema que para ellos es el primario. Esta realización de contacto $[\mathrm{t}+\mathrm{c}]$ alcanza un $84 \%$ en Primer Agua y un 46,43\% en Ranquilhue.

Aunque las instancias de reemplazo caracterizan al fonema originario, también se observan algunas alternancias. Creemos que este dato es relevante, pues sugiere un patrón que sigue el proceso de castellanización de algunos fonemas vernáculos en la zona: los procesos de alternancia de fonos, progresivamente, van cediendo a las instancias de sustitución que podrían terminan desplazando al fonema, a menos que, los niños completen o avancen en su proceso de adquisición de la lengua en su entorno familiar o escolar.

A continuación, entregamos algunos ejemplos de estos procesos.

Ejemplos de reemplazo del fonema $/ \mathrm{ts} /$ por $[\mathrm{t}+\mathrm{c}]$ en Primer Agua y Ranquilhue:

(1) $/$ tsewa/ por ['trewa] "perro"

(2) $/$ tsapi/ por ['trapi] "aj'i”

(3) /kutsal/ por [ $\mathrm{k}^{\mathrm{j} i}{ }^{1}$ tral $]$ "fuego"14

Ejemplos de alternancia de $/ \mathrm{ts} / \sim[\mathrm{t}+\mathrm{c}]$ en Primer Agua $\mathrm{y}$ Ranquilhue:

(1) $/$ tsewa/ ['trewa] "perro"

(2) $/$ tsapi/ ['trapi] "ají"

Como el fonema africado retroflejo $/ \mathrm{t}+\mathrm{r} /$ no existe en cuanto tal en la lengua dominante, era teóricamente esperable

${ }^{14}$ Este ejemplo sólo lo encontramos en Ranquilhue, donde tres niños conocían la palabra "fuego, fogón"; en primer Agua, ningún escolar conocía este ítem. 
un proceso de adaptación que siguiera el patrón fonéticofonológico de ésta, y fue lo que sucedió. El fonema se realizó, principalmente, como una secuencia que es compatible con la fonotaxis del castellano: $/ \mathrm{t}+\mathrm{r} /$, no así con la del mapudungun. Así, los escolares segmentan el fonema /ts/ en dos fonos sucesivos: $[\mathrm{t}+\mathrm{r}]$. Este proceso de desarticulación o descomposición suele suceder con los fonemas o sonidos que no existen más que en uno de los dos sistemas en contacto, y que serán interpretados como sonidos "nuevos" por los hablantes con predominio de la lengua que no lo tiene (Sala, 1988).

\subsection{Resumen de la vitalidad de los segmentos analizados}

A continuación, presentamos un resumen de la vitalidad de los segmentos analizados, a través de dos gráficos. El primero muestra las realizaciones de cada segmento, en relación con las palabras efectivamente respondidas por los niños. El segundo, en cambio, muestra el rendimiento del segmento en relación con el total de palabras consultadas o expectables. Incluimos el segundo gráfico para evitar la lectura distorsionada que podría sugerirse si solo estuviera el primero, representando sólo las escasas palabras respondidas por los niños y no se diera cuenta del rendimiento del segmento según el total de palabras, incluidas las respondidas y las no respondidas por los escolares. 
Marisol Henríquez Barahona.Vitalidad de la fonología segmental del Mapudungun de escolares Mapuches de Tirúa

\section{Gráfico 1.}

Ocurrencia de las realizaciones vernáculas en palabras respondida

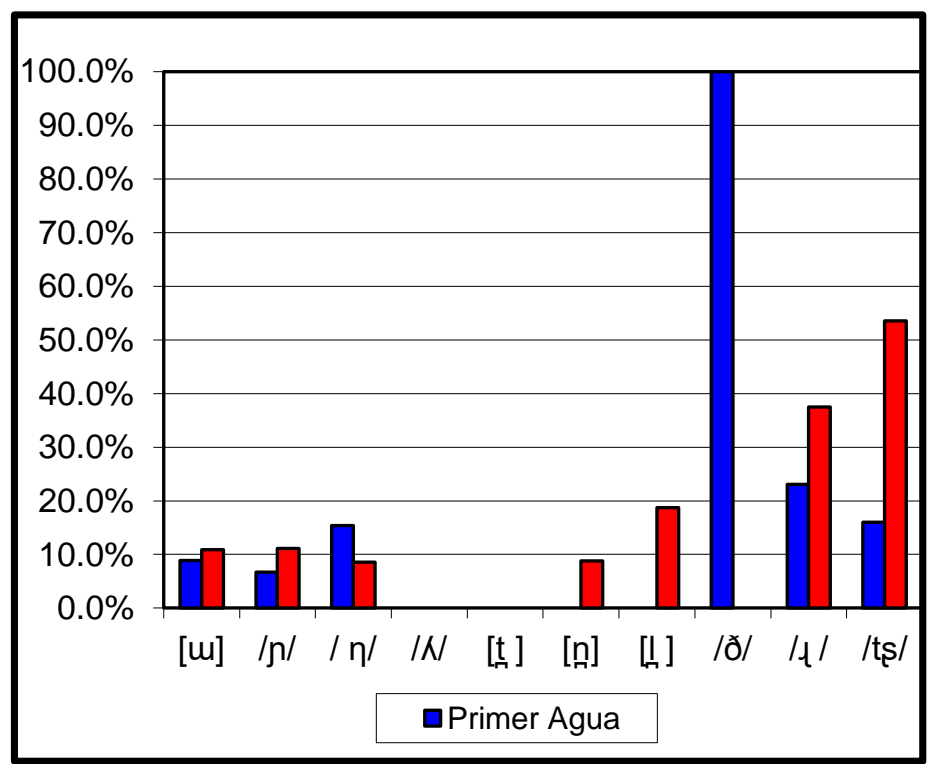




\section{Gráfico 2}

Ocurrencia de las realizaciones vernáculas en total de palabras consultadas:

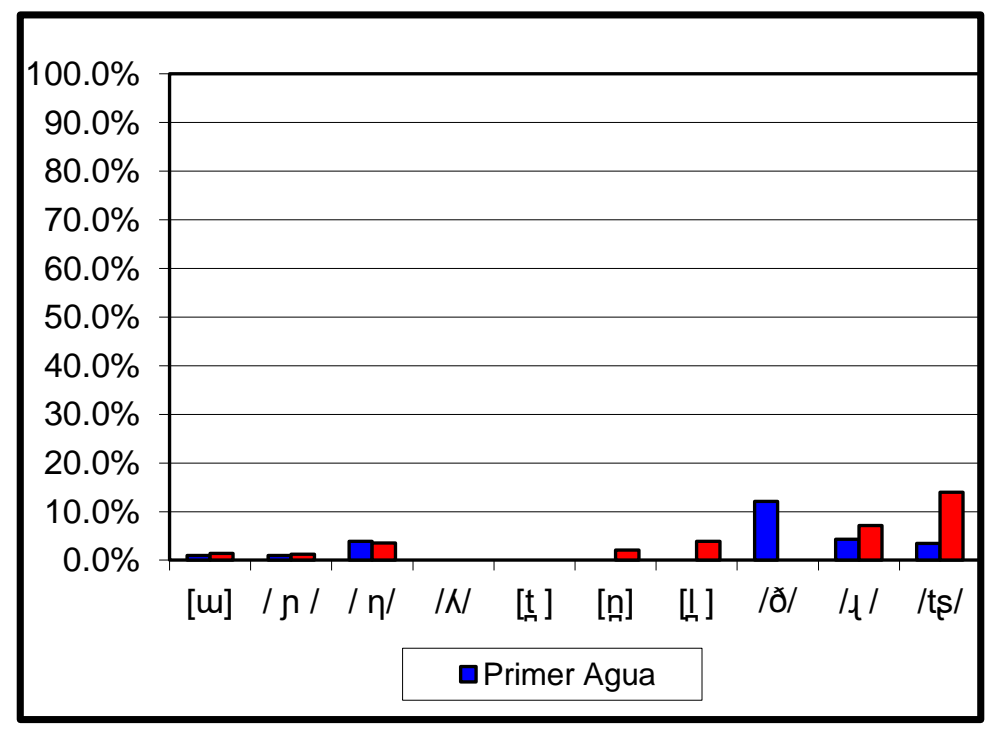

\section{Conclusiones}

Por medio del análisis de los datos, hemos podido constatar la existencia de una serie de rasgos fónicos en el mapudungun que manejan los escolares de Primer Agua y Ranquilhue y que pueden ser atribuidos a la influencia del castellano. En efecto, los procesos de transferencia han provocado una fuerte desestabilización de la mayoría de los segmentos analizados, como es posible apreciar en las tablas y gráficos precedentes 
Por otra parte, se observa que "entre Primer Agua y Ranquilhue" las divergencias son mínimas, pues el grado y difusión de los fenómenos de transferencia y, por ende, la disminución de la vitalidad del sistema fonológico, se visualiza de manera bastante homogénea.

En el análisis conjunto de ambas localidades, destacamos:

- Pérdida de la denominada "sexta vocal mapuche" /u/, hecho que provoca la convergencia del sistema vocálico mapuche con el del español.

- Ausencia del fonema lateral palatal $/ K /$.

- Pérdida de los fonemas (inter)dentales $/ \mathrm{t}, \mathrm{n}, 1 /$.

- Alto grado de desestabilización o pérdida de vitalidad de otros segmentos analizados, entre los que sobresalen la nasal velar $/ \mathbf{y} /$ y la aproximante retrofleja / $/$, los cuales se caracterizan por su baja frecuencia y altos índices de reemplazo. En primer Agua, esta situación se hace extensiva al fonema africado retroflejo /ts/.

- Escasa ocurrencia del fonema nasal palatal sonoro /n/ en el postmargen silábico.

En términos generales, nuestros datos muestran sistemáticas transferencias del castellano, que han provocado la alternancia y, mayoritariamente, el reemplazo de fonemas del mapudungun ausentes en la matriz fonológica de la lengua dominante. Todo esto ha provocado un evidente proceso de desmantelamiento o pérdida fonológica en el mapudungun de los escolares de la zona.

Lo anterior tiene relación directa con los bajos niveles de competencia en mapudungun que tienen estos niños, pues en sus hogares ha decaído el proceso de transmisión natural 
de la lengua ancestral (Henríquez, 2014). Además, el debilitamiento de la norma y las tradiciones lingüísticas de las comunidades de Primer Agua y Ranquilhue se refleja en las vacilaciones o inseguridad en la elección de la variable fonológica por desconocimiento de las formas tradicionales. En otras palabras, hemos constatado la existencia de pérdida fonológica debido al avanzado proceso de desplazamiento lingüístico al que está sometido el mapudungun en la zona.

Estos resultados, al menos en su tendencia general, son coincidentes con los que se obtienen al considerar la vitalidad del léxico y la competencia en la narración del cuento por parte de los escolares del sector. En este sentido, destacamos el alto porcentaje de palabras no respondidas por parte de los niños de ambos sectores: del total de palabras consultadas de la lista léxica, los escolares de Primer Agua conocían un $18,74 \%$ y los de Ranquilhue un $18,46 \%$.

Por último, quisiéramos señalar la relevancia de realizar estudios en la zona con estudiantes que hayan sido objeto de la enseñanza sistemática del mapudungun en sus escuelas, a través de la implementación del subsector de Lengua Indígena; pues en aquellas localidades donde la familia no está siendo protagonista de la enseñanza de la lengua, la escuela podría cumplir un rol relevante. 


\section{Bibliografia}

Alvarez-Santullano, Pilar. Descripción fonológica del Huilliche, un dialecto del mapuche o araucano del centro-sur de Chile. Tesis para optar al grado de Magister en Artes con Mención en Linguística. Universidad de Concepción.1986a. Impreso.

Alvarez-Santullano, Pilar. "Descripción fonemática del Huilliche: estudio comparativo". Alpha 2, (1986b):4550.Impreso.

Andersen, Roger. "Determining the linguistic attributes of language attrition". En Lamber, R. and Freed, B. (eds.), The Loss of Language Skills. Rowley, Mass: Newsbury House Publishers.1982.Impreso.

Blas-Arroyo, José Luis. Sociolingüística del español. Desarrollos y perspectivas en el estudio de la lengua española en contexto social. Madrid: Ediciones Cátedra. 2008.Impreso.

Duran,Teresa; Desiderio Catriquir y Arturo, Hernández, A. "Revitalización del mapunzungun. Una visión crítica desde la educación intercultural, la sociolingüística y la antropología". Patrimonio cultural mapunche. Derechos lingüísticos y patrimonio cultural mapunche Volumen I, Temuco: Universidad Católica de Temuco, 2007. 107-125. Impreso.

Echeverría, Max. "Descripción fonológica del mapuche actual". Boletín del Instituto de Filología de la Universidad de Chile XVI, (1964):13-59. Impreso.

Gimeno, Francisco y María, Gimeno. El desplazamiento lingüístico del español por el inglés. Madrid:

Ediciones Cátedra, 2003. Impreso.

Grinevald, Colette. "Language contact and language degeneration". En F. Coulmas (ed.), The Handbook of Sociolinguistics. Oxford: Basil Blackwell, 1997. 257270. Impreso. 
Gundermannn, Canihuan, Clavería y Faúndez. "Permanencia y desplazamiento, hipótesis acerca de la vitalidad del mapuzugun". RLA 47(2009): 37-60.

Henriquez, Marisol. "Interferencias del sistema fonológico español en el sistema fonológico mapuche de jóvenes hablantes bilingües". RLA 42 (2004): 93-106.Impreso. .Vitalidad fonológica del mapudungun en escolares mapuches pewenches y lafkenches de la VIII región del Bío-Bío. Tesis de Doctorado en Lingüística. Universidad de Concepción, 2013.Impreso.

- "Estado del mapudungun en comunidades pewenches y lafkenches de la región del Bío-Bío: El caso de los escolares". RLA, 52 (2014): 1340.Impreso.

“Ámbitos de uso del mapudungun en comunidades pewenches y lafkenches de la región del Bío-Bío”. Literatura y Lingüística 31, (2015): 185-204.Impreso. ."Estado de la fonología segmental del mapudungun de escolares lafkenches de la comuna de Tirúa: rasgos prominentes". Literatura y Lingüística. (En prensa). Henríquez, Marisol y Gastón, Salamanca. "Vitalidad de la fonología segmental del chedungun hablado por escolares del Alto Bío-Bío”. Alpha, 41, (2015): $207-$ 231.Impreso

."Rasgos prominentes de la fonología segmental del chedungun hablado por escolares pewenches del Alto Bío-Bío”. Alpha, 34, (2012):152-172.

Hernández, Juan y Manuel, Almeida. Metodología de la investigación sociolingüística. Málaga: Comares, 2005.Impreso.

Kirschner, Carl. "Language attrition and the spanish-english bilingual: a case of syntactic reduction". Bilingual Review 21 (1996):123-130. Impreso.

Lagos, Cristian. "El mapudungun en Santiago de Chile: vitalidad y representaciones sociales en los mapuches urbanos". RLA 50 (1), 2012:161-184. Impreso. 
Lagos, Daniel. "El estrato fónico del mapudungu(n)". Nueva Revista del Pacífico 19-20 (1981):42-66. Impreso.

Malvestitti, Marissa; Ana Fernández y Aníbal, DíazFernández. "Sincronía dinámica en la fonología del mapudungun hablado al este de los Andes", en Ana Fernández Garay y Marisa Censabella (editoras): Estudios fonológicos de continua dialectales: mapuche y wichí. Santa Rosa: Universidad de la Pampa, 2009. Impreso.

Moreno Fernández, Francisco. Principios de sociolingüística y sociología del lenguaje. Barcelona: Ediciones Ariel, 2009. Impreso.

Sadowsky, Scott; Héctor, Painequeo; Gastó Salamanca y Heriberto, Avelino. "Mapudungun". Journal of the International Phonetic Association 43(2013):87-96. Impreso.

Sala, Marius. El problema de las lenguas en contacto.

México: Universidad Nacional Autónoma de México, 1988. Impreso.

Salas, Adalberto. "Esbozo fonológico del mapudungu, lengua de los mapuches o araucanos de Chile central". Estudios Filológicos 11(1976):143-153.

."Mapuche-Español. Análisis fonológico contrastivo". VICUS, Cuadernos-Lingüística 2(1978):57-85.

- El mapuche o araucano de Chile. Fonología, gramática y antología de cuentos. Madrid: Fundación MAPFRE América,1992. Impreso.

Salamanca, Gastón. "Fonemas segmentales del pewenche hablado en el Alto Bío- Bío". RLA 35(1997):113124. Impreso.

Salamanca, Gastón y Elizabeth Quintrileo. "Fonemas segmentales y muestra lexical del mapudungun hablado en Tirúa". RLA 47(2009):13-35. Impreso.

Sánchez, Gilberto. "Relatos orales en pewenche chileno". Anales de la Universidad de Chile 17 (1989):289-360. Impreso. 
Silva-Corvalán, Carmen. Sociolingüística y pragmática del español. Washington, DC.: Georgetown University Press, 2001.Impreso.

Suárez, Jorge. "The Phonemes of an Araucanian Dialect". International Journal of American Linguistics ,25 (1959):177-181. Impreso.

Thomason, Sarah. Language contact. Edinburgh: University Press 2001. Impreso.

Thomason, Sarah y Terrence, Kaufman. Language contact, creolization, and genetic linguistics. Bekerley/Los Angeles: University of California Press, 1988. Impreso.

Van Coetsem, Frans: Loan Phonology and theTwo Transfer Types in Language Contact. Dordrecht: Foris, 1988. Impreso.

Weinreich, Uriel. Lenguas en Contacto. Caracas: Universidad Central de Venezuela,1974. Impreso.

Zúñiga, Fernando. "Maudunguwelaymi am? ¿Acaso ya no hablas mapudungun? Acerca del estado actual de la lengua mapuche". Centro de Estudios Públicos 105 (2007):9-24. Impreso. 